International Journal of Current Advanced Research

ISSN: O: 2319-6475, ISSN: P: 2319 - 6505, Impact Factor: SJIF: 5.995

Available Online at www.journalijcar.org

Volume 6; Issue 4; April 2017; Page No. 3488-3492

DOI: http://dx.doi.org/10.24327/ijcar.2017.3492.0300

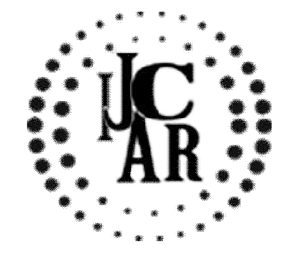

Research Article

\title{
FABRICATING AN EXPERIMENTAL SET-UP TO INVESTIGATED DESIGN AND DEVELOPMENT OF JET TESTER TO CHECK THE EROSION WEAR BEHAVIOR OF COATED AND UNCOATED SS304 AT VARIOUS DISTINCT ANGLES
}

\author{
Vikas Patyal., Amit Singla., Gurmeet Singh and Shubham Sharma
}

Department of Mechanical Engineering, Chandigarh University, DAV University, India

\section{A R T I C L E I N F O}

Article History:

Received $26^{\text {th }}$ January, 2017

Received in revised form $10^{\text {th }}$ February, 2017

Accepted $22^{\text {nd }}$ March, 2017

Published online $28^{\text {th }}$ April, 2017

\section{Key words:}

Verification, jet erosion tester, nozzles, repeatability, slurry erosion, slurry

\begin{abstract}
A B S T R A C T
Erosion leads to loss of life of parts in machinery and pipeline which manage slurry. In order to maximize life proper survival of materials used as required. Slurry erosion jet tester facilities designation of best material under presumption operating terms. Jet erosion is ordinarily victimized to study the proportional erosion behavior of variant material at moderate. Solid, concentration velocity and particle size and input angle. A slurry pot is invented by infixing propeller from the behind of the cylinder and is revolved at the speed requisite for consistent distribution. The specimen are mounted on the test fixture which is rigid has a provision to move in variant angular position to find out the wear at distinct angles. When the high velocity of slurry particles collide with on the specimen that stimulate erosion of material. The experiments are fulfilled for repeatability tests for fix parameters such 55, particle size 655 micron and angle \& $10 \%$ solid concentration for 60 minutes and another one for attestation. The results were acquired for ductile materials and are raise in good transcription with the literature finally, the study leads to an excellent understanding of the influence of various and the jet erosion test contributes result in the future in some calibration of the terms in which these test are performed.
\end{abstract}

Copyright $(2017$ Vikas Patyal et al. This is an open access article distributed under the Creative Commons Attribution License, which permits unrestricted use, distribution, and reproduction in any medium, provided the original work is properly cited.

\section{INTRODUCTION}

Erosion wear is very critical quantity for election and design of slurry transportation system as it impact radially to the economy of hydraulic imparting of solids. Wear is defined as the advancing volume loss of a material from a target surface. It may occur due to corrosion, or erosion. Erosion is stimulated by chemical reactions which can be controlled by accepting appropriate measures, considering that wear is due to erosion can only be minimized by controlling the operative parameters [1]. The last few decades, the service life of apparatus handling solid -liquid mixtures is expressed due to erosion wear and hence efforts have been made to forecast the erosion last of materials . Erosion wear is a complicated manifestation, which hinge upon a large number of parameters. Erosion wear may be outlined as the prevailing experiment which can displace the material form the solid surface. it is due to the appropriate mechanical interaction between the surface and the striking particles in a liquid stream. In the erosion experiment the high pressure energy of slurry particles that means transfer of kinetic energy to the surface. The gaining the kinetic energy of particles at the target surface, it leads to increase the material loss due to erosion [2].

\section{*Corresponding author: Vikas Patyal}

Department of Mechanical Engineering, Chandigarh

University, DAV University, India
It builds upon the predominant impact angle of particle impingement with the material surface $\&$ it will vary from 0 to 90 degrees. The impact angle built upon both fluid and particle- particle interaction. This type of wear can be actually establish in slurry pumps, angled pipe bends turbines, pipes and pipe fitting, nozzles, burners etc. the material loss due to erosion increases with the increase in kinetic energy of the particles striking at the target surface[3].

\section{Slurry erosion}

Slurry can be related as a mixture of solid particles in a liquid (usually water) of such a degree of density that it can be readily pumped. The word slurry erosion is purely defined as that type of a wear or loss of mass, that is process by a material opened to a high velocity stream of slurry [4].

\section{Parameter's Affecting on Erosion Wear}

Impact angle (angle between the target surface and direction of impacting velocity of particles) Hardness (it is the mysterious effect on the surface of the material) Velocity of solid particle (it depends upon the particle size, shape) Solid concentration (it is the percentage by weight or volume) [4]

\section{LITERATURE REVIEW}

Wai and T.Miyajima (2006) [5] investigated the study of erosion wear resistance. The author has investigated the new 
type solid impact test to know the properties of wear. The properties of wear are single layered and multi layered coatings. In PVD coatings, the 1.2 micrometer alumina parts are impacted at high velocity at different angles, different speed and different substrate temperature. And the result shows the coated materials has good wear properties than substrate materials.

Girish R. Desale and B.K Gandhi (2009) [6] investigated on erosion wear behavior of laser clad surfaces. They studied about the colmonoy- 6 and Inconel 625 is cladded on AISI 316L steel and AISI 304L steel. The author were optimized the laser processing parameters. They obtained scanning speed and power feed of a sound clad. They found that the minimum cracks porosity and distortion were found at scanning speed of $0.1 \mathrm{~m} / \mathrm{min}$. and powder rate $12 \mathrm{~g} / \mathrm{min}$. as the result shows the maximum hardness is obtained by colmonoy6 clad on AISI316L steel and is $352 \mathrm{VHN}$ in case of other steel.

HS Grewal and Anupam Agarwal (2012) [7] examined the studied of high velocity slurry corrosion test rig. The author designed a new type of slurry erosion test rig with various types of construction and working condition. They eliminate the some limitations such as velocity concentration, acceleration; distance, etc. the results ductile and brittle materials erosion wears behaviors being observed.

Satish and Bhushan (2014) [8] investigated on development of jet tester. They used stainless steel SS3041 at uniform speed distribution. They studied about the different types of material which is used slurry pot tester. The various parameters such as velocity, particle size and impact angle affect the material of the slurry pot tester. The result obtained ductile material ductile material is good material. Promod A. Thakur and Hitesh (2015) [9] investigated about the development of jet erosion tester.
They found that high velocity particle strike with specimen through the nozzle that causes the erosion wear. The author conducted experiments for repeatability test for fix parameters such as $45^{\circ}$ and particle size does not more than 615 micron, angle and $10 \%$ solid concentration for 60 minutes. As the results were obtained the ductile materials are in good arrangement.

\section{Development of Jet Tester}

The test rig belongs of authoritative part namely as slurry pot. This slurry pot look like a conical shape has a capacity 7.2 liter. We can developed a slurry pot by desale et al. (2005). The main operation of slurry pot to get ready a homogenous mixture of distinct particle sizes and distinct concentrations. After organizing the homogenous mixtures of distinct combinations and then the slurry pot has a stirrer. a stirrer is revolving with help of 3A.C motor and it has a maximum capacity of $1440 \mathrm{rpm}$. With the help of 3 phases dimmer stat (Transformer) the revolving speed of motor is controlled. The apparatus has a centrifugal pump which has 2HP capacity of kirloskar pumps. The centrifugal pump absorb the slurry from the slurry pot and provide the high pressure slurry to the converging section of the nozzle having $10 \mathrm{~mm}$ diameter where its pressure energy is converted in to the velocity of fluid.

There is one control valve also connected to ascendance the mass flow rate of the mixture. The work piece holder (fixture), has an settlement to runs in distinct pointed positions. One tin hopper is also connected to the apparatus which helps to restrain the diffusing mixture in to the work environment. The function of hopper to gather the mixture after striking on the work piece and drops back to the recirculate mixture to the slurry pot.

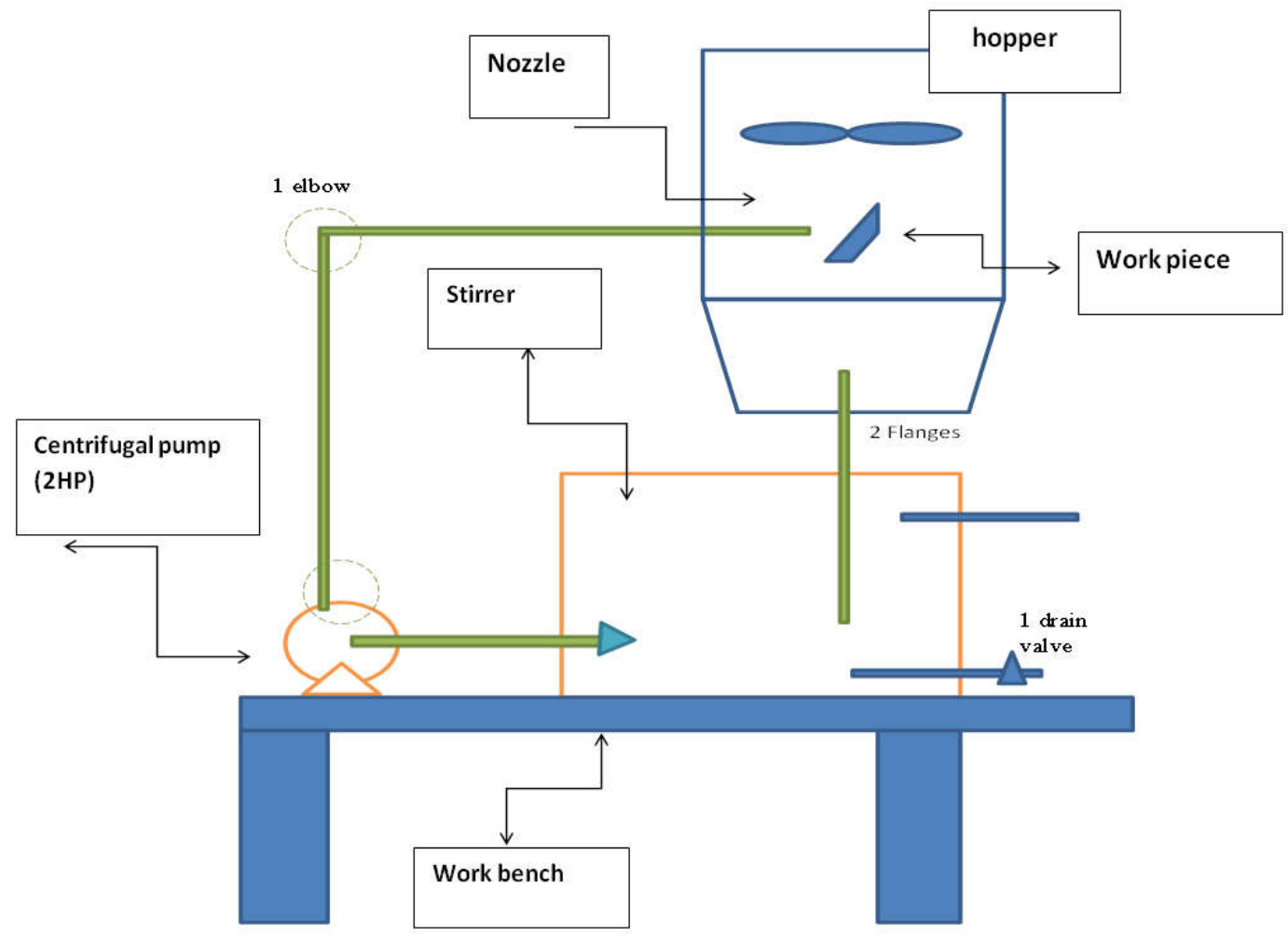

Fig.1 Schematic Diagram of Jet Tester 
The test rig has the main part that is the frame structure which sustain or detention the whole assembly and stirrer motor.

\section{Particle Size Division}

The particle size division is vital to install the variation in the particles of solid sample particles percentage present in distinct size ranges. Hence the coarser particles, sieve decomposition used to determine the particle size distribution. With the help of dry sieve decomposition mode distribution has been obtained. The comprised sample of the solid particle is assumed and sieving is done with a set of sieves. The main particular case is taken to insure that the sample is strictly dried. The sample maintained on each sieve is collected and its percentage should be calculated by under mentioned the standard procedure.

In this present examination the sand particles is collected as solid material for the present exploration and the physical parameters are given in the table.1. In solid particles the indistinguishable sized particles are not selected. The sieved particles using successive sieves sizes and the selected between two successive sieves are designated by the mean sieve size.

Selecting the quartz particles, we can take two grades namely grade 1 and grand 2 of Indian standard sand were used. The mean particle size of 655 was collected as the material retained between two sieves of 600 and 710 sizes.

WC-10Co-4Cr powder was exquisite as coating material by HVOF technique. The substrate material was exquisite as SS304. SS304 has a large number of application in various industrial sectors. The SS304 has unmatched combination of more excellent mechanical properties and toughness. There is such limitations related to SS304 which is poor wear and erosion resistance regards its engineering applications. The work piece has the micro hardness which was evaluated using Vickers hardness-tester. We lay upon the load of $100 \mathrm{~g}$ for $10 \mathrm{~s}$ was adopted for both specimens. During this performance the micro defect must not be shown in the indenters mark.

\section{Parametric Value of Work Piece and Nozzle Testing}

\begin{tabular}{cc}
\hline Parameter & Value Tested \\
\hline Nozzle length & $50.8 \mathrm{~mm}$ \\
Inlet angle & $60^{\circ}$ \\
Nozzle diameter & $1.14 \mathrm{~mm}$ \\
Orifice diameter & $0.38 \mathrm{~mm}$ \\
Water pressure & $310 \mathrm{Mpa}$ \\
Abrasive flow rate & $3.8 \mathrm{~g} / \mathrm{s}$ \\
Dimensions of specimen & $25 \mathrm{~mm}^{*} 25 \mathrm{~mm} * 6.5 \mathrm{~mm}$ \\
Time & Max. 4 hours \\
Stand of distance & $45 \mathrm{~mm}$ \\
\hline
\end{tabular}

Table 1 Physical parameters of erodent used

\begin{tabular}{|c|c|c|c|c|c|c|}
\hline Sr. & Solid pa & $\begin{array}{c}\text { Chemical } \\
\text { formula }\end{array}$ & Colour & $\begin{array}{c}\text { Sp. } \\
\text { Gravity } \\
\left(\mathrm{kg} / \mathrm{m}^{\wedge} 3\right)\end{array}$ & $\begin{array}{c}\text { Hardness } \\
\text { VHN }\end{array}$ & $\begin{array}{c}\text { Particle } \\
\text { shape }\end{array}$ \\
\hline 1 & $\begin{array}{c}\text { Quartz(IS } \\
\text { sand)\& fly ash }\end{array}$ & & White\& & 2652 & & $\begin{array}{c}\text { Sub } \\
\text { angular }\end{array}$ \\
\hline
\end{tabular}

Table 2 Mechanical properties of stainless steel 304

\begin{tabular}{|c|c|c|c|c|c|}
\hline \multirow[b]{2}{*}{ grade } & \multirow[b]{2}{*}{$\begin{array}{c}\text { Tensile } \\
\text { strength }\end{array}$} & \multirow{2}{*}{$\begin{array}{c}\text { Yield } \\
\text { strength } \\
0.2 \% \\
\end{array}$} & \multirow[b]{2}{*}{$\begin{array}{c}\text { Elongation } \\
(50 \mathrm{~mm}) \mathrm{min}\end{array}$} & \multicolumn{2}{|c|}{ Hardness } \\
\hline & & & & $\begin{array}{c}\text { Rockwell } \\
\text { B(HRB)max }\end{array}$ & $\begin{array}{c}\text { Brinell } \\
\text { (HB)max }\end{array}$ \\
\hline SS 304 & 515 & 205 & 40 & 92 & 201 \\
\hline
\end{tabular}

Table 3 Elemental composition of target material material used

\begin{tabular}{ccccccccccc}
\hline \multirow{2}{1}{1} & $\begin{array}{l}\text { Stainless } \\
\text { steel 304 }\end{array}$ & $\mathbf{P}$ & $\mathbf{C}$ & $\mathbf{M n}$ & $\mathbf{S}$ & $\mathbf{C r}$ & $\mathbf{N i}$ & $\mathbf{M o}$ & $\mathbf{N}$ \\
& 0.045 & 0.08 & 2.0 & 0.030 & 20.0 & 0.10 & - & 0.10 \\
\hline
\end{tabular}

Table 4 Range of parameter for preliminary examination study

\begin{tabular}{cccccc}
\hline $\begin{array}{c}\text { Sr.no Target material } \\
\text { Investigation } \\
\text { type }\end{array}$ & $\begin{array}{c}\text { Impact angle } \\
\text { degree }\end{array}$ & $\begin{array}{c}\text { Particle } \\
\text { size(m) }\end{array}$ & $\begin{array}{c}\text { Solid particles } \\
\text { Solid concentration } \\
\text { by wt\% }\end{array}$ & Time(min.) \\
\hline 1 Stainless steel 304 Repeatability $30^{\circ}, 45^{\circ}, 60^{\circ}, 75^{\circ}, 90^{\circ}$ & & Quartz(sand) & 30 to 60 & 60 min. \\
\hline
\end{tabular}

\section{Experimental Results}

\section{Effect of Different Impact angles on Erosion Wear}

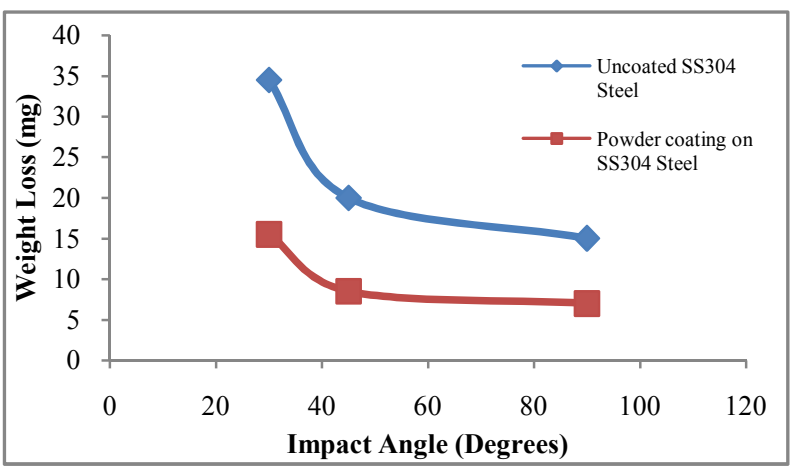

Figure 1 Shows variation in weight loss with respect to different impact angle at different flow rate.

\section{Effect of $30^{\circ}$ Impact angle on Erosion Wear}

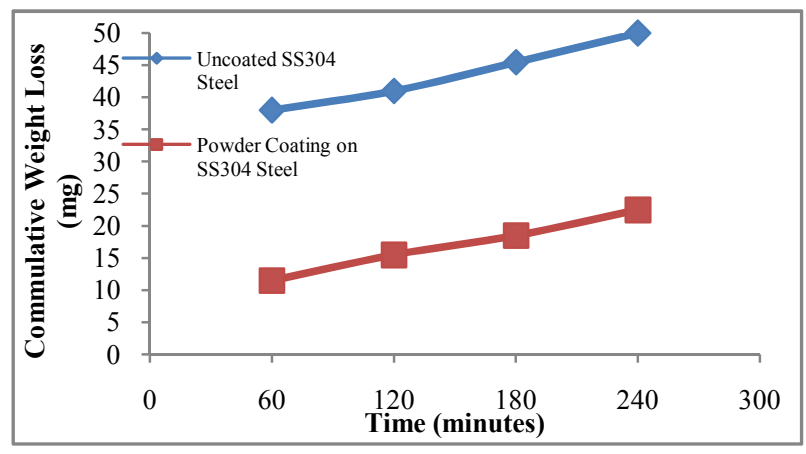

Figure 2 Shows Variation in cumulative weight loss with respect to time at $30^{\circ}$ impact angle at a flow rate of 2.5 litres/second.

\section{Effect of $45^{\circ}$ Impact angle on Erosion Wear}

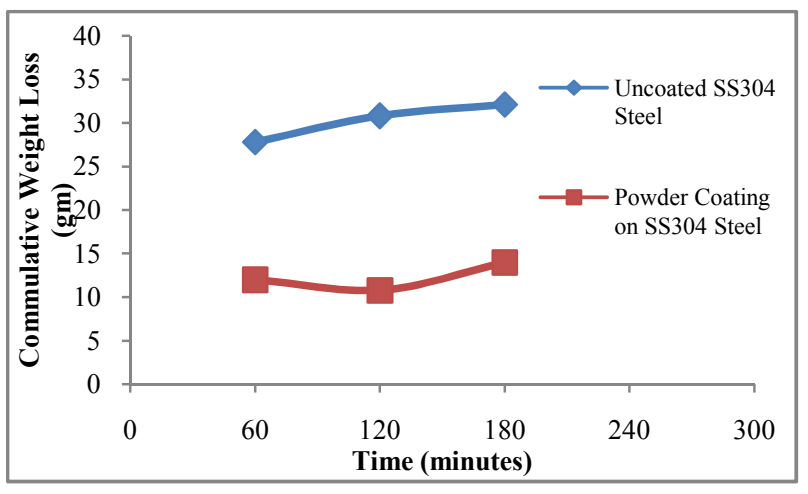

Figure 3 shows Variation in cumulative weight loss with respect to time at $45^{\circ}$ impact angle at a flow rate of 2.5 litres/second. 
Effect of $60^{\circ}$ Impact angle on Erosion Wear

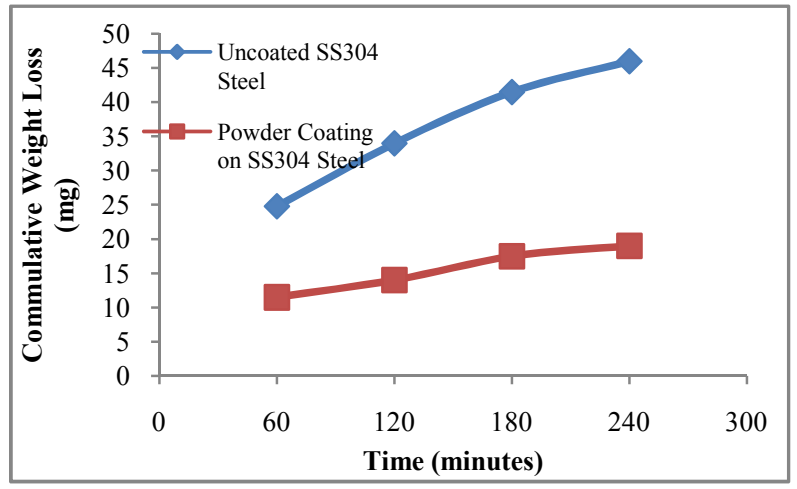

Figure 4 shows Variation in cumulative weight loss with respect to time at $60^{\circ}$ impact angle at a flow rate of 2.5 Litres/second.

Effect of $75^{\circ}$ Impact angle on Erosion Wear

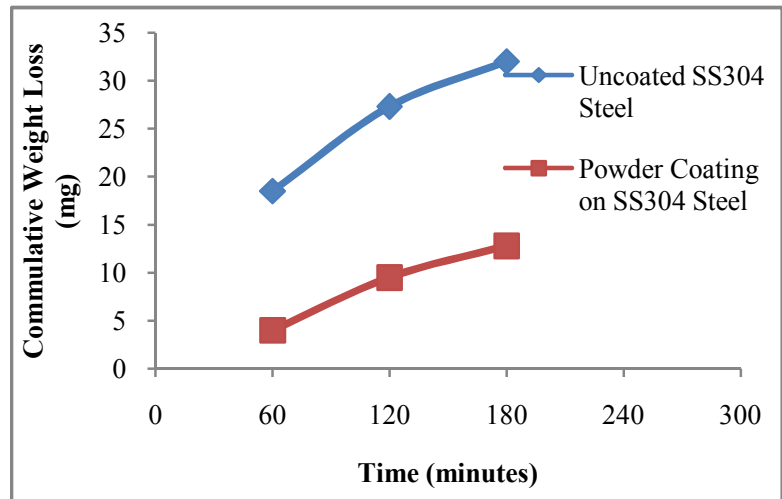

Figure 5 shows Variation in cumulative weight loss with respect to time at $75^{\circ}$ impact angle at a flow rate of 2.5 Litres/second.

\section{Effect of $90^{\circ}$ Impact angle on Erosion Wear}

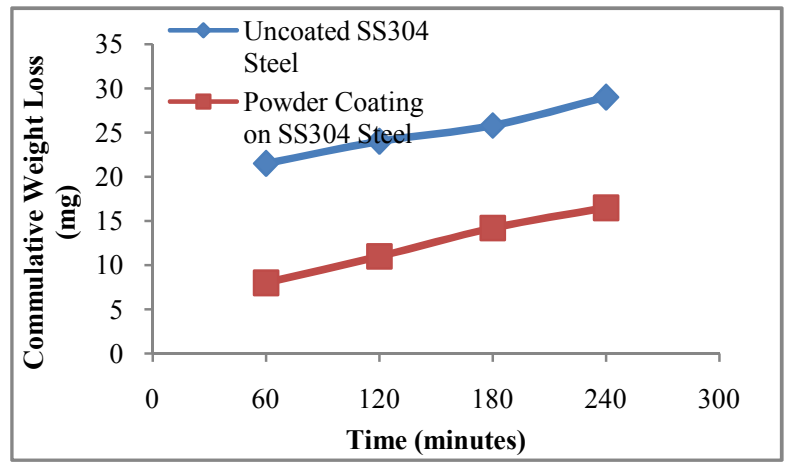

Figure 6 shows Variation in cumulative weight loss with respect to time at $90^{\circ}$ impact angle at a 2.5 litres/second.

\section{Effect of time on Erosion Wear}

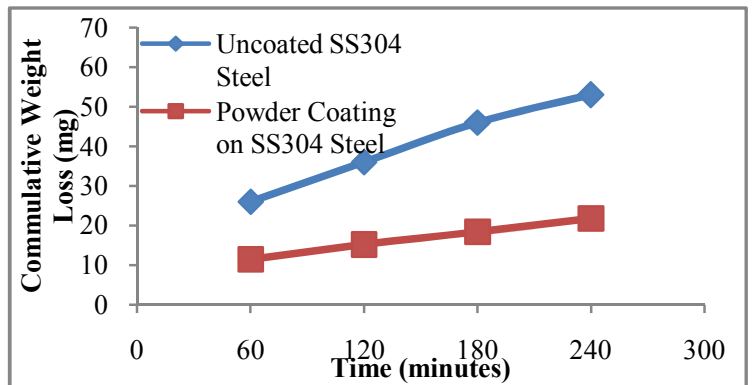

Figure 7 shows Variation in cumulative weight loss and time at a flow rate of $3.5 \mathrm{lit} / \mathrm{sec}$

\section{Experimental Operation}

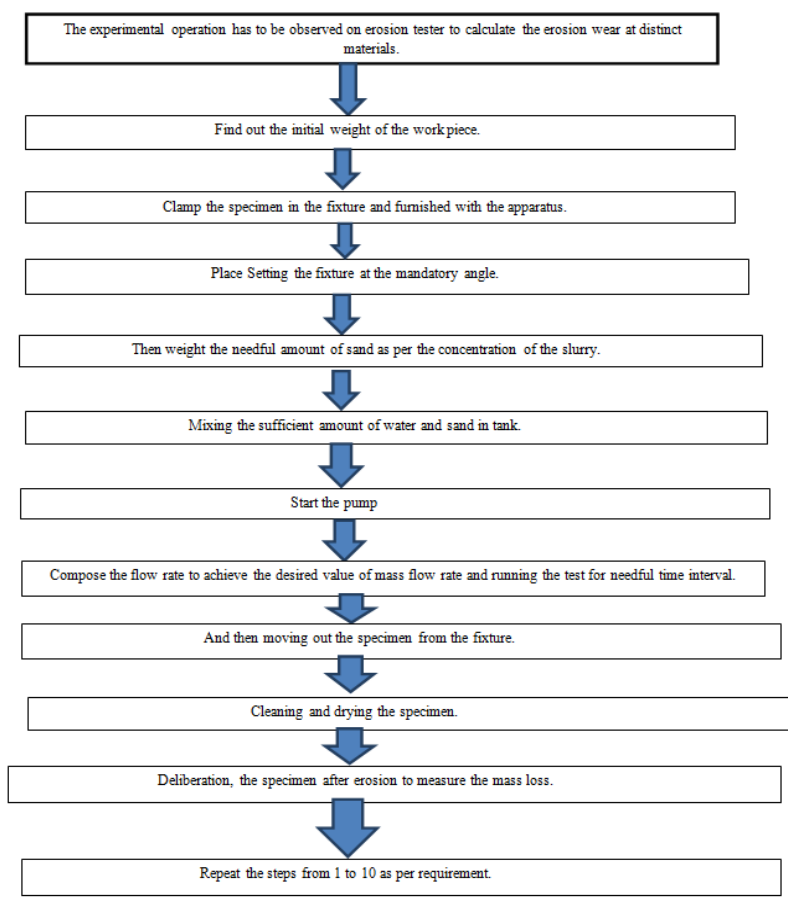

Effect on impact angle on erosion wear

\begin{tabular}{|c|c|c|c|c|c|c|c|c|c|c|}
\hline \multirow{2}{*}{ Time hr } & \multicolumn{10}{|c|}{ Impact angle } \\
\hline & \multicolumn{2}{|c|}{$30^{\circ}$} & \multicolumn{2}{|c|}{$45^{\circ}$} & \multicolumn{2}{|c|}{$60^{\circ}$} & \multicolumn{2}{|c|}{$75^{\circ}$} & \multicolumn{2}{|c|}{$90^{\circ}$} \\
\hline 1 & 38 & 11.5 & 27.8 & 12 & 24.8 & 11.5 & 18.5 & 4 & 21.5 & 8 \\
\hline 2 & 41 & 15.5 & 30.8 & 10.8 & 34 & 14 & 27.3 & 9.5 & 24 & 11 \\
\hline 3 & 45.5 & 18.5 & 32.1 & 14 & 41.5 & 17.5 & 32 & 12.8 & 25.8 & 14.2 \\
\hline
\end{tabular}

\section{CONCLUSION}

Hence The yield strength of coated steel 304 is more as equivalently to uncoated steel. And it has better corrosion resistance. Increasing the thickness of coating decreases the porosity and increase the rate of hardness. Appropriate compostion of nickel and chromium is the good for improved the slurry wear resistance. More than two times better performance than uncoated steel.

\section{Refercences}

1. A.N.J Stevenson and I.M.Hutching. The influence of nozzle length on the divergence of the erodent particle stream in a gas- blast erosion rig (1995).

2. R.J.K Wood and D.W Wheeler. Design and performance of a high velocity air-sand jet impingement erosion facility (1997)

3. Y.Xie, H.Mcl.Clark. Modeling slurry particles dynamics in the coriolis erosion tester (1999).

4. Sandeep kumar and Vikram singh. Analysis of erosion wears on coated and uncoated ductile material (2016).

5. H.Meng and Neville. Investigated the corrosion study of stainless steel in marine conditions (2006).

6. H.Mg and X.Hu. Systematic erosion-corrosion study of two and $\mathrm{SS}$ in marine condition via experimental design (2007).

7. Girish and Desale and B.K Gandhi. Erosion wear behavior of laser clad surfaces of low carbon austenitic steel (2009). 
Fabricating An Experimental Set-Up To Investigated Design And Development Of Jet Tester To Check The Erosion Wear Behavior Of Coated And Uncoated Ss304 At Various Distinct Angles

8. HS Grewal and Anupam Agrwal. Design and Development of high velocity slurry erosion test rig using CFD (2012).

9. Satish and Bhushan. Development of pot tester to simulate the erosion wear due to solid- liquid Mixture (2014).
10. Pramod and Hitiesh. Development slurry erosion jet tester to simulate the erosion wear due solid-liquid mixture (2015).

\section{How to cite this article:}

Vikas Patyal et al (2017) ' Fabricating An Experimental Set-Up To Investigated Design And Development Of Jet Tester To Check The Erosion Wear Behavior Of Coated And Uncoated Ss304 At Various Distinct Angles', International Journal of Current Advanced Research, 06(04), pp. 3488-3492.

DOI: http://dx.doi.org/10.24327/ijcar.2017.3492.0300 